\title{
BMJ Open Family group decision-making interventions in adult healthcare and welfare: a systematic literature review of its key elements and effectiveness
}

\author{
Chantal F Hillebregt, ${ }^{\oplus 1}$ Eline W M Scholten, ${ }^{\oplus 1}$ Marcel W M Post, ${ }^{\oplus 1,2}$ \\ Johanna M A Visser-Meily, ${ }^{\oplus 1,3}$ Marjolijn Ketelaar ${ }^{\circledR 1}$
}

To cite: Hillebregt CF, Scholten EWM, Post MWM, et al. Family group decisionmaking interventions in adult healthcare and welfare: a systematic literature review of its key elements and effectiveness. BMJ Open 2019;9:e026768. doi:10.1136/ bmjopen-2018-026768

- Prepublication history and additional material for this paper are available online. To view these files, please visit the journal online (http://dx.doi org/10.1136/bmjopen-2018026768).

Received 20 September 2018 Revised 29 January 2019 Accepted 13 February 2019

Check for updates

(C) Author(s) (or their employer(s)) 2019. Re-use permitted under CC BY-NC. No commercial re-use. See rights and permissions. Published by BMJ.

For numbered affiliations see end of article.

Correspondence to Dr Marjolijn Ketelaar; M.Ketelaar@dehoogstraat.nl

\section{ABSTRACT}

Background Family group decision-making (FGDM) is a structured decision-making process, aiming to shift the balance of power from professional towards the person in need and their family. It differentiates from other familycentred meetings by the presence of three key elements: (1) plan with actions/goals, (2) family driven, (3) three phases of meetings gradually increasing empowerment. FGDM studies are increasing in different settings in adult healthcare/welfare, although effectiveness is unknown at this date.

Objectives (1) to systematically review the presence of the three FGDM key elements in family-centred interventions in adult care and welfare, (2) to evaluate the effectiveness of FGDM interventions.

Design Systematic review.

Data sources and eligibility criteria A total of 14 relevant electronic databases and 1 academic search machine were searched until February 2018. First, familycentred studies were selected with controlled trial designs in adult healthcare/welfare. Second, interventions were categorised as FGDM if all three key elements were present.

Data extraction and synthesis Studies were examined concerning their (1) characteristics (2) quality/level of evidence (3) presence of FGDM key elements and (4) results.

Results Six articles from three studies on family-centred interventions were selected from a total of 1680 articles. All were of low quality. One study (two articles) met all criteria for an FGDM intervention, describing the efficacy of family group conferences among social welfare recipients on mental health outcomes. Although the intervention group showed significantly better outcomes after 16-23 weeks; no differences were seen at the 1-year follow-up.

Conclusions Controlled studies of both family-centred interventions and FGDM are still low in quantity and quality. No conclusions on FGDM effectiveness can be drawn. Further high-quality intervention studies are required to evaluate the impact of FGDM on adults in need, including their families; as well as evaluation research detecting possible barriers and facilitators influencing FGDM implementation.

PROSPERO registration number CRD42017077585.

\section{Strengths and limitations of this study}

- This is the first review of the effectiveness of family group decision-making (FGDM) intervention studies in adult healthcare and welfare to date.

- A search of 14 relevant electronic bibliographic databases was conducted which gives this review breadth and comprehensiveness.

- Studies were only assessed when written in the English language.

- Identification of FGDM studies only when all three FGDM key elements were present.

- Narrative analyses because of heterogeneous studies and few high-quality studies.

\section{BACKGROUND}

Family group decision-making

The family group decision-making (FGDM) model is implemented in child care and welfare in more than 30 countries worldwide. ${ }^{1}$ The roots of FGDM originate from the family group conference (FGC) model in New Zealand ${ }^{1}$ where it was legislated as the decision-making process to be used in cases of child abuse, neglect and youth offending in $1989 .^{23}$ Since then, the model is subject to change resulting in many variants with a range of models, ${ }^{4}$ which all can be referred to under the umbrella of the broader term FGDM. ${ }^{5}$ While outside the USA, meetings are referred to as FGCs, within the USA, different variants are named such as: family unity meeting, team decision-making meeting, family decision meeting, family team conferences and family team meeting. ${ }^{46-12}$

In FGDM the person in need and members of their family reflect on goals with respect to participation in daily activities through structured meetings. The term 'family' is widely interpreted with the inclusion of extended family members, friends, neighbours and significant others. ${ }^{13}$ During FGDM, the 


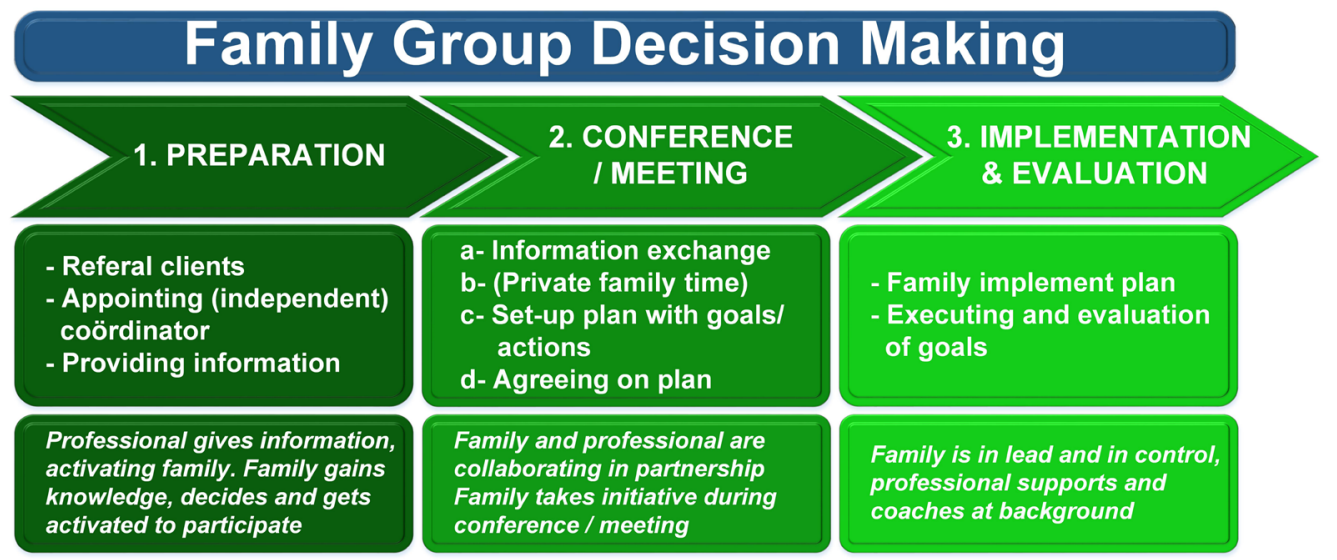

Figure 1 Key elements of family group decision-making. ${ }^{26}$

participants share ideas on possible solutions to achieve goals and decide on a concrete plan to support the person in need in the way he or she wants. The ownership of this plan remains with the family; they are responsible for contributing, controlling and executing the actions/goals of the plan including inviting people they want to the conference, with little contribution from professionals. In this way, FGDM aims to stimulate the decision-making process, with a rearrangement of tasks and responsibilities to shift the balance of power from the professional towards the person in need and the family within this decision-making process. ${ }^{14}$ FGDM is expected to facilitate the assessment of problems into a new perspective where the family and the person in need have the main voice in matters that concern them, ${ }^{15}$ enlarging their empowerment. ${ }^{16}$ Major advantages are that FGDM uses resources already existing within society namely the family and others, ${ }^{17}$ who are often better able to find workable solutions $^{14}$ consistent with their own culture, lifestyle and history than professionals. ${ }^{18}$

Families often experience the FGCs as very positive and helpful. ${ }^{19} 20$ Various process evaluations in child care, for instance, show that participants feel listened to ${ }^{1}$ and are satisfied, ${ }^{21}$ even though a recent meta-analysis of FGC (one of the variants of FGDM) involving fourteen controlled studies, showed no effectiveness in child-related outcomes. ${ }^{7}$

\section{Key elements of FGDM}

All variants under the umbrella of FGDM have a common philosophy ${ }^{5}$ of engaging the family with a central role in the decision-making process, ${ }^{82-24}$ characterised by three key elements. These key elements are important because they indicate the difference between FGDM and more general family-centred meeting interventions. The first key element is the importance of drawing up an action plan serving as a basis for the action-oriented perspective and to clarify, monitor and achieve goals. Second, the understanding that FGDM decision models are 'family driven', meaning that the approach is not aimed at the family, but achieves results through the contributions of the family. The person in need together with the family set the agenda, develop and implement the plan. They possess the executive role rather than the professional. Here, FGDM distinguishes itself from 'traditional' approaches of family meetings that are often 'family centred ${ }^{15}$ where the professional remains in their executive role.

The third important key element is the three phases characterising the FGDM process ${ }^{825}$ 26; the preparation phase, the conference phase and the evaluation phase (see figure 1). Through these meetings, a gradual shift takes place in the balance of power from professional towards increased empowerment of the person in need and their family. In the preparation phase, the referral commences and the concept of FGDM is explained to the person in need and their family and a conference coordinator is appointed. In the original FGC model dating from the 1980s, the key values of having an independent coordinator and private family time ${ }^{1}$ are quite fixed. However, these can vary between the different FGDM types. ${ }^{49}$ Depending on the type of FGDM, this coordinator can be a member of an independent agency or the family may decide, based on their preference for example to a member of the professional team. ${ }^{21}{ }^{27}$ In the conference phase, the actual FGDM takes place in which the person in need and the family members reflect on their goals and the support needed to make these goals achievable. Depending on the FGDM type, the family can choose if they want to schedule private family time, without professionals being present, to develop a concrete action plan. ${ }^{21} 27$ In the evaluation phase, the achievements resulting from the goals and action plan are evaluated.

\section{FGDM in the adult healthcare/welfare}

Involving the family in adult healthcare and welfare is not new and is implemented in a number of settings. Predischarge and follow-up family meetings are conducted in geriatric medicine, rehabilitative medicine, palliative care and psychiatry, ${ }^{28-32}$ for instance. These meetings are often held to improve communication between the multidisciplinary team and family members discussing 
patient's health condition and progress. ${ }^{33}$ In some healthcare settings like rehabilitation medicine, a goal-directed programme, using an action plan and a predetermined set of preparation and evaluation meetings, is already part of the regular rehabilitation programme. Although two out of three key elements characterising the FGDM process $^{82526}$ (action plan and the meeting set-up in three phases) are present, these meetings do not qualify as FGDM. One of the important differences with FGDM is that these family meetings lack the family-driven key element. Despite the fact that the family is often engaged in the decision-making process setting up a plan; the coordination of tasks and the ownership of the plan remains with the professionals. ${ }^{293435}$ First, more awareness is needed to understand the importance of distinguishing the more commonly implemented family-centred meetings and FGDM by its key elements. Second, with FGDM studies slowly increasing within different settings among adults in public mental healthcare, ${ }^{8}{ }^{36-39}$ rehabilitation medicine ${ }^{40}$ general social welfare ${ }^{41-43}$ and social welfare for elderly, ${ }^{445}$ it is important to systematically examine the effectiveness of FGDM. To our knowledge, such a review has not been published in adult healthcare and welfare to date.

\section{OBJECTIVES}

The objectives of the present study are: (1) to systematically review the presence of the three key elements of FGDM in family-centred interventions in adult care and welfare, and (2) to evaluate the effectiveness of the FGDM interventions.

\section{METHODS}

\section{Research design and methodology}

We followed the systematic review methodology using the Preferred Reporting Items for Systematic Reviews and Meta-Analyses statement ${ }^{46}$ and the Cochrane Handbook for Systematic Reviews of Interventions ${ }^{47}$ which specify different phases concerning the search strategy and screening (preparation phase, title/abstract screening, full-text screening and extraction) ${ }^{47}$

\section{PATIENT INVOLVEMENT}

As this is a review screening literature, no patients/clients are involved.

\section{Data sources and search strategy}

A comprehensive search of 14 relevant electronic bibliographic databases and 1 academic search engine (Google Scholar), was conducted (PubMed/Medline, CINAHL, PsycINFO, Cochrane Library, International Bibliography of the Social Sciences, Campbell library, Social Science Research Network, ASSIA Applied Social Sciences Index and Abstracts, Social Care Online, sociological abstracts/social services abstracts, Web of Science,
Scopus, SocINDEX, ERIC). It was a deliberate choice to only include the intervention eligible criteria into the search strategy, including most common variants of the intervention FGDM (see online supplementary appendix 1, example full electronic search strategy). Articles not eligible to the other criteria were screened out within the title abstract phase. This resulted in a broad screening process aiming to be as thorough and accurate as possible. The search string was adapted for use with different bibliographic databases. All articles were searched until 21 February 2018, with no further predetermined date limitation. Only studies in the English language were included.

\section{Eligibility criteria}

The PICOCS process framework ${ }^{48}$ was used to formulate the eligibility criteria according the concepts: Population, Interventions, Comparators, Outcomes, Context and Study design.

Studies were included if they met the following eligibility criteria:

- Types of population (P): The target population of the study is aged eighteen or older.

- Types of interventions (I): We used a two-step selection approach. Aim 1: family-centred interventions including FGDM. Aim 2: only FGDM interventions. For the first aim, we selected all family-centred studies, defined as studies of interventions to engage family/ friends in the decision-making process. Furthermore, we screened these family-centred studies for the presence of the three FGDM key elements ((1) plan with goals/actions, (2) family-driven, (3) three phases). For the second aim, we included only interventions qualified as FGDM with all three key elements present.

- Comparators $(\mathrm{C})$ : Treatment as usual or no treatment was identified as comparator.

- Types of outcomes (O): All outcomes were included. Studies must have included at least one quantifiable outcome measure.

- Context (C): Any setting that serves for adult healthcare or welfare.

- Types of study design (S): Studies using controlled trial designs (randomised and non-randomised) with a comparison group.

\section{Screening}

\section{Preparation phase}

The citation management software programme Mendeley was used to import studies from the 14 electronic bibliographic databases. One masterfile was created merging the studies of the 14 databases after removing all duplications. All articles were uploaded to the systematic literature review software Rayyan ${ }^{49}$ where studies were categorised and labelled according a predetermined coding scheme. 
Title abstract and full-text screening

All articles were first selected in which some kind of engagement of family/friends in the decision-making process was described. We have named these 'family-centred studies'. All family-centred studies were further screened for eligibility according to the other eligibility criteria (eg, population, study design, etc). When a decision could not be made based on title and abstract, the full paper was obtained for detailed assessment.

One researcher performed the title abstract screening $(\mathrm{CFH})$ with $10 \%$ double-screening (EWMS). Inconsistencies were discussed with a third researcher (MK) until consensus was reached. The full-text screening was conducted by two researchers (CFH 100\%; EWMS and MK 50\% each). Inconsistencies were discussed until consensus was reached.

Data extraction, methodological quality and level of evidence

The remaining studies were extracted and $100 \%$ double assessed (CFH/EWMS) concerning their (1) characteristics, (2) quality/level of evidence and (3) presence of the key elements of FGDM: (1) plan, (2) family driven, (3) three phases. The identification of the FGDM key elements was deliberately postponed to the data extraction phase instead of the full-text screening phase. Consequently, an overview of family-centred outcome studies versus FGDM intervention studies can be presented as support for our first research aim.

A standardised data extraction form from the Cochrane Collaboration ${ }^{47}$ was used to extract the following data from the eligible studies: author, year, country, design, sample, cohort, intervention, measures, main findings, limitations.

The quality of the studies was determined using the Quality Assessment Tool for Quantitative Studies ${ }^{50}$ judged to be suitable in systematic reviews of effectiveness. ${ }^{450}$
The tool assesses six domains: (1) selection bias, (2) study design, (3) confounders, (4) blinding, (5) reliability and validity of data collection method; and (6) withdrawals/drop-outs. With use of the tools guideline, ${ }^{51}$ a global quality score can be calculated ranging from 1 to 3 , with 1 being the best score reflecting no 'weak' domain rating; 2 reflecting one 'weak' rating and 3 reflecting two or more 'weak' ratings ${ }^{50}$ (see table 1 ).

The level of evidence was checked using the classification developed by the Oxford Centre for Evidence-Based Medicine ${ }^{5253}$ ranking the studies conform their probability of bias $^{54}$ (conform the study design criteria, only level 1 and 2 studies are included) (see table 2).

\section{RESULTS \\ Screening \\ Preparation/identification}

The search yielded a total of 3356 hits retrieved from the database searches. After removing duplicate citations $(n=1676)$, a total of 1680 unique records were left. The articles were published in the time period ranging from 1948 to 2018 (see figure 2).

\section{Title abstract and full-text screening}

A total of 1680 articles were screened in the title/abstract search conform all eligible criteria, including the first step of the intervention eligible criteria (family-centred studies). In total, 1669 articles were excluded on studies in another context (consumer purchase decision-making, marital decision-making, etc) that did not meet the study design criteria of pertaining a controlled trial, did not meet the population criteria of the participant being adult, were not family centred, had no abstract and full text (inaccessible information of meetings, conferences, etc) and were non-English. The 10\% double screening

Table 1 Quality Assessment Tool for Quantitative Studies ${ }^{50}$

\begin{tabular}{|c|c|c|c|}
\hline Components & Strong & Moderate & Weak \\
\hline Selection bias & $\begin{array}{l}\text { Very likely to be representative } \\
\text { of the target population } \\
\text { and } \geq 80 \% \text { participation rate }\end{array}$ & $\begin{array}{l}\text { Somewhat likely to be representative } \\
\text { of the target population and } 60 \%- \\
79 \% \text { participation rate }\end{array}$ & $\begin{array}{l}\text { All other responses or not } \\
\text { stated }\end{array}$ \\
\hline Design & Randomised controlled trial and CCT & $\begin{array}{l}\text { Cohort analytic, case-control, cohort } \\
\text { or an interrupted time series }\end{array}$ & $\begin{array}{l}\text { All other designs or design not } \\
\text { stated }\end{array}$ \\
\hline Confounders & $\begin{array}{l}\text { Controlled for at least } 80 \% \text { of } \\
\text { confounders }\end{array}$ & $\begin{array}{l}\text { Controlled for } 60 \%-79 \% \text { of } \\
\text { confounders }\end{array}$ & $\begin{array}{l}\text { Confounders not controlled for, } \\
\text { or not stated }\end{array}$ \\
\hline Data collection methods & Tools are valid and reliable & $\begin{array}{l}\text { Tools are valid but reliability not } \\
\text { described }\end{array}$ & $\begin{array}{l}\text { No evidence of validity or } \\
\text { reliability }\end{array}$ \\
\hline
\end{tabular}

CCT, controlled clinical trial. 


\begin{tabular}{|c|c|}
\hline Level & Type of evidence \\
\hline $1 \mathrm{~A}$ & $\begin{array}{l}\text { Systematic review (with homogeneity) } \\
\text { of randomised controlled trials (RCTs) }\end{array}$ \\
\hline $1 \mathrm{~B}$ & Individual RCT (with narrow Cls) \\
\hline $1 \mathrm{C}$ & All or none study \\
\hline $2 \mathrm{~A}$ & $\begin{array}{l}\text { Systematic review (with homogeneity) of cohort } \\
\text { studies }\end{array}$ \\
\hline 2B & $\begin{array}{l}\text { Individual cohort study (including low-quality RCT, } \\
\text { eg, }<80 \% \text { follow up) }\end{array}$ \\
\hline $2 \mathrm{C}$ & 'Outcomes' research. Ecological studies \\
\hline $3 \mathrm{~A}$ & $\begin{array}{l}\text { Systematic review (with homogeneity) of case- } \\
\text { control studies }\end{array}$ \\
\hline 3B & Individual case-control study \\
\hline 4 & $\begin{array}{l}\text { Case series (and poor quality cohort and case- } \\
\text { control study) }\end{array}$ \\
\hline 5 & $\begin{array}{l}\text { Expert opinion without explicit critical appraisal } \\
\text { or based on physiology bench research or 'first } \\
\text { principles' }\end{array}$ \\
\hline
\end{tabular}

(CFH/EWMS) showed good inter-rater agreement $(85 \%$ consensus; kappa=0.61)..$^{55}$

A total of 11 articles were double checked on the eligibility criteria (CFH/EWMS/MK). Non-consensus articles were discussed until consensus was reached. In total, five studies did not meet the following eligibility criteria: study design $(\mathrm{n}=3),{ }^{31}{ }^{56}{ }^{57}$ population $(\mathrm{n}=1)^{58}$ and no full text $(\mathrm{n}=1){ }^{59}$

\section{Data extraction and quality assessment}

Of the remaining six family-centred articles, ${ }^{41}{ }^{42} 60-63$ data were extracted and summarised concerning their (1) characteristics, (2) quality/level of evidence and (3) presence of the key elements of FGDM (see table 3).

\section{Characteristics of extracted family-centred studies}

All six articles reported information conform the PICOCS process frame work ${ }^{48}$ eligibility criteria. However, the heterogeneity in outcome, context, intervention and participants was high and the results varied greatly. Therefore, it was not possible to analyse the articles quantitatively. Instead, the data extraction tool ${ }^{47}$ formed the basis of a narrative synthesis.

The articles were published between 2011 and 2017. The six articles originated in total from three studies, emanated in Norway from Malmberg-Heimonen and Johansen, ${ }^{41}{ }^{42}$ the Netherlands from Joling et al. ${ }^{60-62}$ and the USA from de Havenon et al. ${ }^{63}$ Two studies had a randomised controlled trial (RCT) design, one study was a pilot controlled trial. Different context fields were described: mental health, dementia care and intensive care unit.

There was a widespread of sample sizes: ranging between 22 and 192 participants. There were three groups of study participants who were questioned on different outcome variables: social welfare recipients, caregivers and patients dyads and family members. The comparison condition for the studies was either treatment as usual or no treatment. The outcome measures for the Malmberg-Heimonen and Johansen study ${ }^{41}{ }^{42}$ were prominently self-reported questionnaires measuring social support, life satisfaction and mental health of social recipients. The study conducted by Joling $e t a l^{60-62}$ reported nursing home placements, depression, anxiety and cost-effectiveness. The study by de Havenon et $a b^{63}$ described a family meeting survey reporting the satisfaction with audio-visual family meetings.

\section{Quality/level of evidence of the extracted family-centred outcome} studies

With use of the Quality Assessment tool for quantitative studies, ${ }^{50}$ six domains were assessed from the three studies: (1) selection bias, (2) study design, (3) confounders, (4) blinding, (5) reliability and validity of data collection method and (6) withdrawals/drop-outs (see online supplementary appendix 2 for detailed information). The $100 \%$ double screening (CFH/EWMS) resulted in $88 \%$ consensus with a very good inter-rater agreement of 0.81 (kappa score).$^{55}$

Although two of the three eligible studies had a strong study design (RCT), the overall quality of the three studies was low. All studies reported challenges with a low participation rate $(<60 \%)$ of the initial eligible group participants or presented no documentation of the participation rate. The low participation rate also affected the level of evidence, ${ }^{52} 53$ resulting in level $2 B$ studies $(n=2)$ and level 2C ( $\mathrm{n}=1)$ (see table 3$)$.

Furthermore, blinding of participants was in all studies not possible due to the nature of the intervention. To conclude, limited information was available on the reliability and validity of used data collection methods.

\section{Presence of FGDM key elements in family-centred interventions}

To examine the presence of the three key elements of FGDM in family-centred interventions in adult care and welfare (see table 4); all six articles of the three studies were $100 \%$ double screened (CFH/EWMS) and resulted in a good inter-rater agreement $(83 \%$ consensus with kappa of 0.67). ${ }^{556465}$ Some differences in agreement were found in labelling the key elements of the Joling et al study. ${ }^{60-62}$ It was not instantly clear if the study was family driven and had a set-up of a plan with actions/ goals.

The family meetings intervention consisted of two individual sessions with the primary caregiver and four family counselling sessions including family members and friends. ${ }^{60-62}$ Aims were to improve emotional and instrumental support given to the patient by relieving the burden of caregiving through mobilising the existing family networks of the patient and primary caregiver; teach problem-solving techniques as well as offer psychoeducation to the primary caregiver. The counsellor (professional) led the family meetings in a directing 


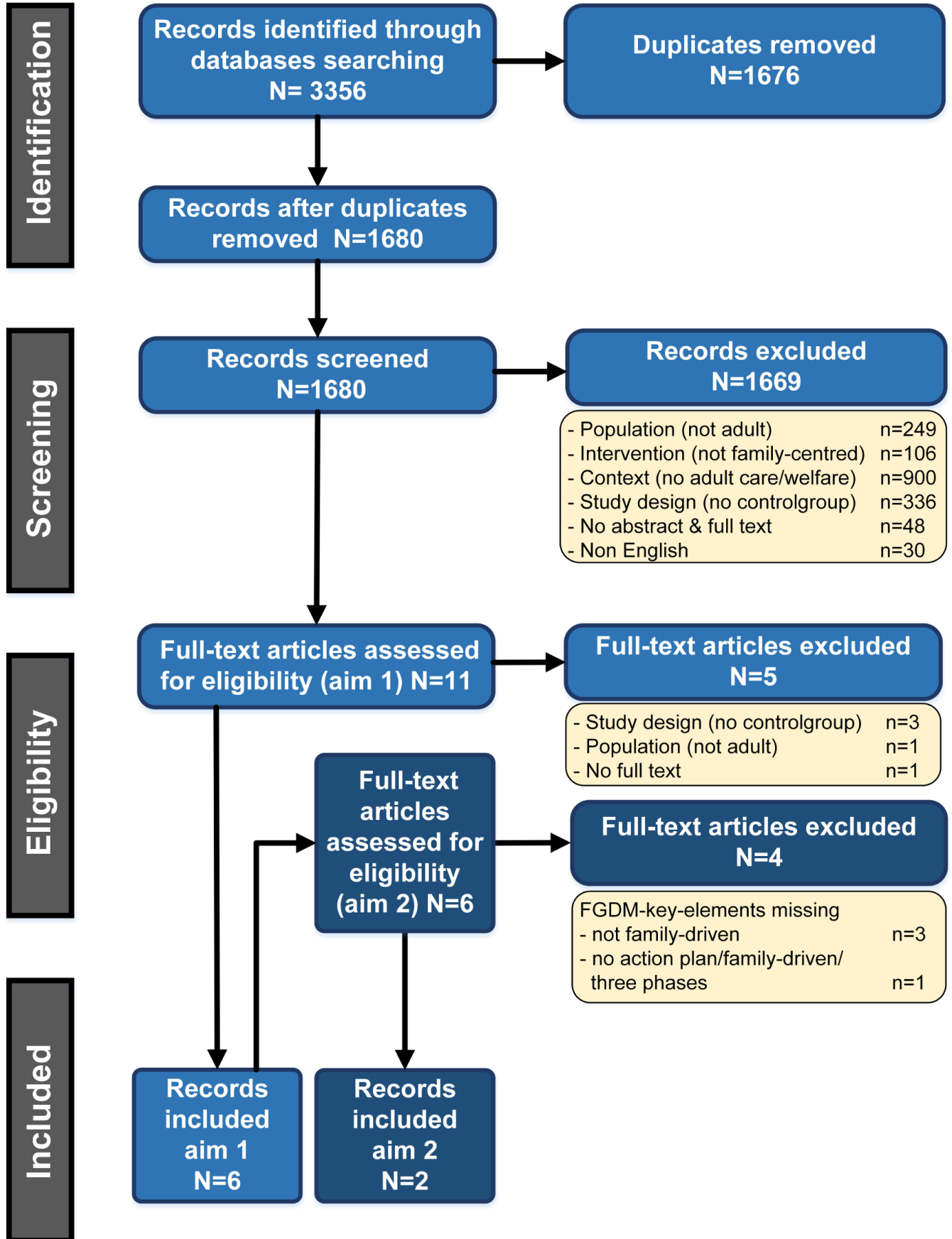

Figure 2 Flow chart of search and selection process. ${ }^{46}$ FGDM, family group decision-making.

role. Consequently, we cannot speak of a family-driven approach. Although the extended family is mobilised, increasing tasks, commitment and family support, it was not clarified what exactly the support consisted of. Therefore, we examined additional information in a manual written for family meetings counsellors. ${ }^{66}$ In the manual, a plan was mentioned but the ownership of the plan remained with the professionals. They set the agenda, leading the meeting. In summary, although the set-up of an action plan and three phases of the meetings could be identified (preparatory meetings with the caregiver, family meetings with family and friends and an evaluation meeting), the study did not meet with the FGDM key element of a family-driven approach.

de Havenon et a ${ }^{63}$ compared audio-visual family meetings versus in-person family meetings with both a set-up initiated by professionals to enhance discourse and decision-making with the patients family members to facilitate medical decisions. Consequently, we cannot speak of a family-driven approach. The other FGDM key elements (action plan, three phases) were also not present.

The Malmberg-Heimonen and Johansen study ${ }^{41} 42$ implemented a FGC model with the following characteristics: (1) it is the participant's meeting, he/she is in 


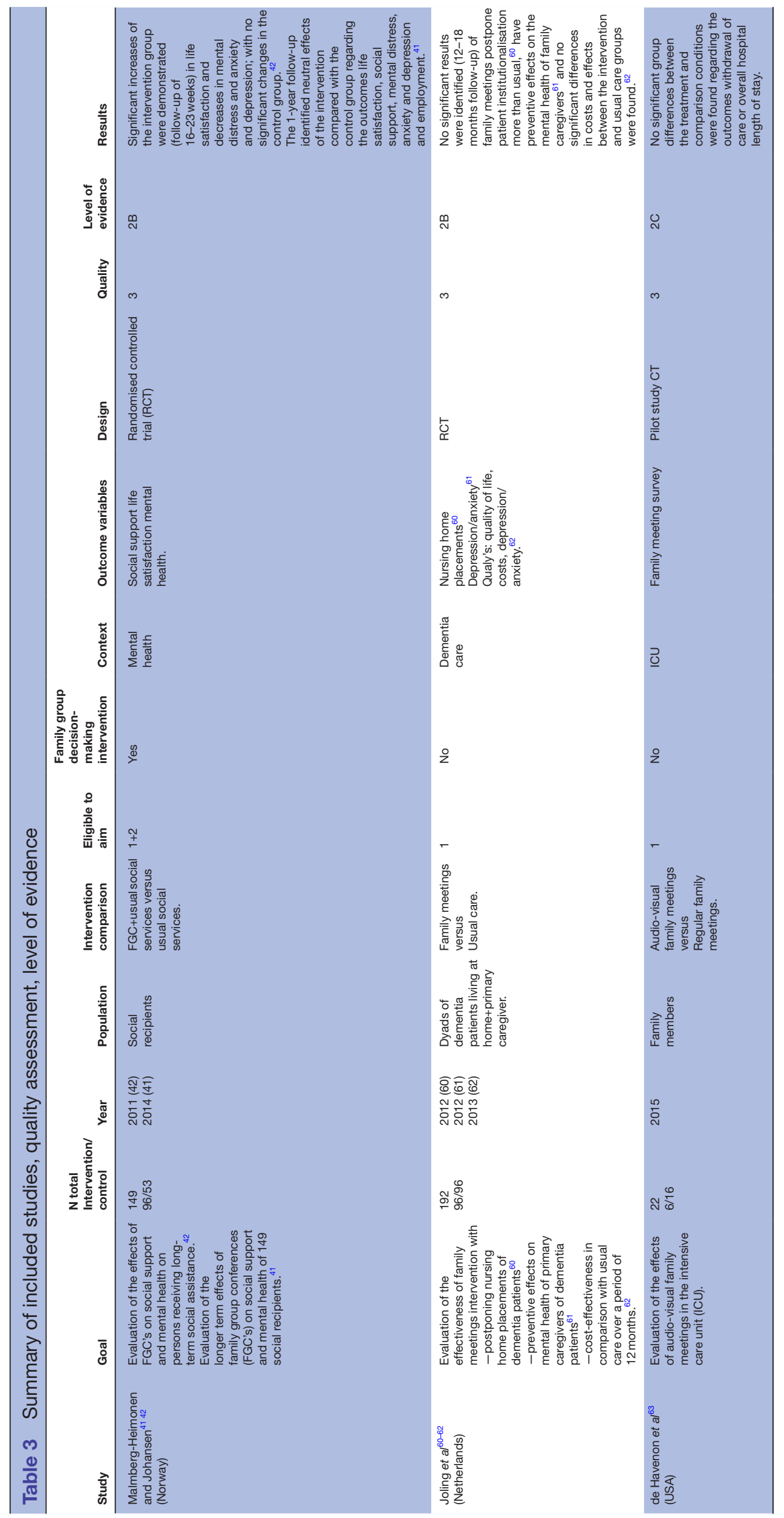

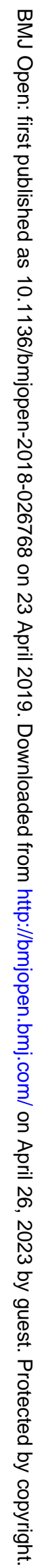


Table 4 Overview of eligible studies to the FGDM key elements

\begin{tabular}{|c|c|c|c|c|}
\hline & \multirow{3}{*}{$\begin{array}{l}\text { Title/abstract phase } \\
\text { Family-centred studies }\end{array}$} & \multicolumn{3}{|c|}{ Extraction phase } \\
\hline & & \multicolumn{3}{|c|}{ FGDM key elements } \\
\hline & & Plan & Family driven & Three phases \\
\hline Malmberg-Heimonen and Johansen ${ }^{41} 42$ & $x$ & $x$ & $x$ & $x$ \\
\hline Joling et $a l^{60-62}$ & $\mathrm{X}$ & $X^{*}$ & $--^{*}$ & $x$ \\
\hline de Havenon et $a^{63}$ & $x$ & - & - & - \\
\hline
\end{tabular}

${ }^{*}$ Information found in additional family meetings manual. ${ }^{66}$

FGDM, family group decision-making.

charge and decides who is invited; (2) the participant gets assistance from an independent FGC facilitator (not employed by the same organisation); (3) the extended network of the participant is invited; (4) private time: extended network discusses alone in the second part of the meeting without members of public organisations; (5) The FGC process results in an action plan.

One meeting is divided into three parts: (1) information part; (2) the meeting between the participant and his or her private network; (3) the concluding part. In summary, we can speak of a family-driven intervention where all FGDM key elements are met.

\section{Evaluation of the effectiveness of FGDM interventions}

For the purpose of evaluating the effectiveness of FGDM interventions, only two papers of the Malmberg-Heimonen and Johansen study were included, ${ }^{41}{ }^{42}$ since the Joling et al and de Havenon et al studies were excluded for having not all ${ }^{60-62}$ or none ${ }^{63}$ of the FGDM key elements present. The study described the effectiveness of FGC among social welfare recipients regarding the outcomes life satisfaction, social support, mental distress, anxiety and depression and employment. ${ }^{4142}$ Although there were significant increases regarding the outcome measures of the intervention group after a follow-up period of 16-23 weeks; the 1-year follow-up identified neutral effects of the intervention compared with the control group. It can be concluded that the positive effect faded away with time. $^{41}$

\section{Discussion and implications for future research}

The first aim of this review was to systematically review the presence of the three key elements of FGDM ${ }^{26}$ (plan with actions/goals, family driven, three phases of meetings) in family-centred interventions in adult care and welfare. An extensive search of 1680 articles from 14 databases resulted in six articles on three studies of family-centred interventions. One study ${ }^{41}{ }^{42}$ possessed all the key elements required to qualify as FGDM. Of the two other family-centred interventions, ${ }^{60-63}$ key elements of FGDM (in particular the family-driven element) were missing. This might be exemplary for family meetings in adult healthcare/welfare. Although the patient and family may be engaged in the decision-making process, the way these meetings are organised fails to really put the patient and family in the drivers seat. Often there are also multifactorial reasons related to decision-making processes such as personal factors as well as, clinician/ professional and organisational factors. ${ }^{67}$ More research is needed in the requirements and the desire to 'upgrade' these meetings to a next level from a collaborative to a family-driven model where the professional remains low profile and supports the family in order for them to take over the executive role.

The second aim was to evaluate the effectiveness of FGDM interventions in adult healthcare/welfare. While the one intervention study ${ }^{41}{ }^{42}$ described short-term effectiveness of FGDM among social welfare recipients, this effect was neutralised after the 1-year follow-up. ${ }^{41}$ Reciprocal interaction seemed difficult to maintain over time, indicating the importance of offering follow-up meetings shortly after the first FGC, sharing responsibility and accountability to fulfil the action plan. ${ }^{3811}$

The lack of rigorous studies of effectiveness of FGDM in adult healthcare/welfare limited answering the second aim. Regardless, this evaluation still adds to our body of knowledge of FGDM in adult healthcare and welfare. Primarily, it highlights the need for high-quality controlled trials. To gain further understanding in the reasoning behind the lack of outcome research, it might be wise to look at the development of FGDM outcome research conducted in child healthcare, which has overcome its own share of obstacles. First, we need to recognise that outcome research of FGDM interventions only started off in the last decennia. It was not until the year 2000 when one of the first controlled studies ${ }^{68}$ was published internationally, comparing FGC intervention versus regular treatment. ${ }^{21}$ Second, multiple studies reported challenges detecting the efficacy of FGDM through time. ${ }^{69}$ Researchers faced difficulties including enough family group conferencing cases to evaluate, resulting in a small sample size. ${ }^{21}$ Furthermore, there was a lack of ability to follow people and their outcomes over a long period of time, this made them unable to measure the long-term effect. ${ }^{69}$ Third, researchers faced challenges conducting high-quality controlled trials using scientific research methods in a socially complex environment with many unpredictable influencing factors as is often the case in a clinical practice setting. ${ }^{69} 70$ Lastly, the only conducted meta-analysis of FGDM in child care included 14 controlled trials from 2000 to 2016, overall showing 
no overall effectiveness in child-related outcomes. ${ }^{7}$ The majority of the included articles were low in quality and were limited in information on programme fidelity. The authors stressed the importance of gathering information on programme fidelity making it able to understand a lack of effect due to possible poor implementation. ${ }^{7}$ Indeed, this review also both reveals the urgency of high-quality controlled trials but simultaneously highlights the need to evaluate their implementation to gain more understanding of influencing factors such as possible barriers and facilitators. Exploring experiences and opinions of both patients, family and professionals who are already participating in the FGDM-meetings is essential and highly needed. The fact is that despite the low quantity and evidence of FGDM outcome research, there is a widespread use and enthusiasm for the implementation of FGDM worldwide in more than thirty countries to date. ${ }^{1}$ These future directions in research can accelerate new comprehension and acknowledgement that shifting the balance of power from professional towards the person in need and their family is most essential in democratising healthcare and welfare.

\section{Limitations}

Several limitations to this systematic review need to be acknowledged. First is the inability to assess studies written in languages other than English, leading to potential selection bias. Nevertheless, we think that the majority of the studies could be assessed, only a small amount of studies were written in a language different than English.

The second limitation concerns the operationalisation used to identify the FGDM meetings.

We only identified FGDM studies when demonstrating meetings involving extended family in the decision making process with the three key elements of FGDM present ((1) plan, (2) family driven, (3) three phases). We have made the decision to integrate the most described key elements with general consensus found in literature, which can frame the outcome of the review. Third, all extracted studies scored low on their quality assessment score and the heterogeneousness was high in both types of population, intervention, context and outcomes. This made mutual comparison of the studies difficult.

Last, it was quite a challenge to identify the intervention eligibility criteria of the articles. The majority of the articles provided limited information about the actual intervention; there was often a lack of detail reporting specific characteristics and content of the intervention. For example, no articles were found to have implemented the Template for Intervention Description and Replication (TIDieR) guidelines, ${ }^{71}$ a 12 -item template to explain and elaborate on the intervention improving quality.

\section{CONCLUSION}

This is the first review to systematically differentiate FGDM interventions from other family-centred interventions and evaluate its effectiveness within the adult population.
Although the studies are still low in both quantity and quality, we have gained an understanding of the differences of FGDM and family-centred intervention studies by means of the identification of the FGDM key elements. The majority of the extracted studies (2/3) are still using the collaborative model of engaging patients and family in the decision-making process instead of the family-driven perspective whereby the professional remains low profile and supports the family in order for them to take over the executive role. These results might be exemplary for a lot of family meetings in the adult healthcare/welfare.

We could not sufficiently answer our second aim regarding the effectiveness of FGDM among adults due to the lack of outcome studies in the adult healthcare/ welfare. Further high-quality intervention studies are required to evaluate the impact of FGDM on adults in need, including their families. Moreover, insight into barriers and facilitators influencing FGDM will support our understanding how to empower persons in need, further democratising healthcare and welfare.

\section{Author affiliations}

${ }^{1}$ Center of Excellence for Rehabilitation Medicine Utrecht, Brain Center University Medical Center Utrecht, and De Hoogstraat Rehabilitation, Utrecht, The Netherlands 2Department of Rehabilitation Medicine, University Medical Center Groningen, University of Groningen, Groningen, The Netherlands

${ }^{3}$ Department of Rehabilitation, Physical Therapy Science \& Sports, UMC Utrecht Brain Center, University Medical Center Utrecht, Utrecht, The Netherlands

Acknowledgements We are grateful to Sana Fazel, Neuroscience and Experimental Psychology at University of Sussex, Brighton, England, for the English proofreading of our manuscript.

Contributors CFH developed the first version of the manuscript, in collaboration with EWMS, JMAV-M, MWMP and MK. JMAV-M, MWMP and MK supervised the writing process and provided feedback on several drafts of the manuscript. EWMS and MK executed the double screening. JMAV-M, MWMP and MK provided methodological advice. CFH wrote the final version of the manuscript.

Funding This study is financially supported by ZonMw, the Netherlands Organisation for Health Research and Development, Fonds Nuts Ohra and Revalidatiefonds, grant number: 630000003 .

Competing interests None declared.

Patient consent for publication Not required.

Provenance and peer review Not commissioned; externally peer reviewed.

Data sharing statement The data that support the findings of this study are available from the corresponding author, (MK), upon reasonable request.

Open access This is an open access article distributed in accordance with the Creative Commons Attribution Non Commercial (CC BY-NC 4.0) license, which permits others to distribute, remix, adapt, build upon this work non-commercially, and license their derivative works on different terms, provided the original work is properly cited, appropriate credit is given, any changes made indicated, and the use is non-commercial. See: http://creativecommons.org/licenses/by-nc/4.0/.

\section{REFERENCES}

1. Frost $\mathrm{N}$, Abram F, Burgess $\mathrm{H}$. Family group conferences: context, process and ways forward. Child Fam Soc Work 2014;19:480-90.

2. New Zealand Legislation. Children, young persons, and their families act. Annu Rev Popul Law 1989.

3. Merkel-Holguin L, Marcynyszyn LA. The complexity of fidelity in measuring system change: the case of Family Group decision making. Br J Soc Work 2015;45:724-36.

4. Rauktis ME, Bishop-Fitzpatrick L, Jung $N$, et al. Family group decision making: Measuring fidelity to practice principles in public child welfare. Children and Youth Services Review 2013;35:287-95. 
5. Sheets J, Wittenstrom K, Fong R, et al. Evidence-based practice in family group decision- making for Anglo, African American and Hispanic families. Child Youth 2009.

6. Helland J. Family group conferencing literature review. Child Youth Off Br Columbia 2005.

7. Dijkstra S, Creemers HE, Asscher JJ, et al. The effectiveness of family group conferencing in youth care: A meta-analysis. Child Abuse Negl 2016;62:100-10.

8. de Jong G, Schout G, Abma T. Examining the Effects of Family Group Conferencing with randomised controlled trials: the golden standard? Br J Soc Work 2015;45:1623-9.

9. Nixon P, Burford G, Quinn A, et al. A survey of international practices policy and research on family group conferencing and related practices. 2005.

10. Abramson-Madden A. In: Pennell J, Anderson G, Widening the circle: thepractice and evaluation of family group conferencing with children, youths, and their families: J Sociol Soc Welf, 2007.

11. Burford G, Pennell J. From agency client to community-based consumer: The Family Group Conference as a consumer-led group in child welfare. handbook of social work with groups. New York, NY, US : Guilford Press, 2004:415.

12. Burford G, Connolly M, Morris K, et al. Introduction, principles, and processes: Part of a larger review of family group conferencing research, 2000.

13. Sundell K, Vinnerljung B. Outcomes of family group conferencing in Sweden. Child Abuse Negl 2004;28:267-87.

14. Lupton C. User Empowerment or Family Self-Reliance? The Family Group Conference model. Br J Soc Work 1998;28:107-28.

15. Merkel-Holguin L. Sharing power with the people: Family group conferencing as a democratic experiment. J Sociol Soc Welf 2004;31:155-73.

16. Aujoulat I, d'Hoore W, Deccache A. Patient empowerment in theory and practice: polysemy or cacophony? Patient Educ Couns 2007;66:13-20.

17. de Jong G, Schout G. Family group conferences in public mental health care: an exploration of opportunities. Int J Ment Health Nurs 2011;20:63-74

18. Jackson S, Morris K. Family Group Conferences: user empowerment or family self-reliance?-a development from Lupton. Br J Soc Work 1999;29:621-30.

19. Asscher JJ, Dijkstra S, Stams GJ, et al. Family group conferencing in youth care: characteristics of the decision making model, implementation and effectiveness of the Family Group (FG) plans. BMC Public Health 2014;14:154.

20. Backe-Hansen EH. Hvordan virker familieråd? Et internasjonalt perspektiv. "How does Family Group counseling work? An international perspective." Hva er det med familieråd? Samlerapport fra prosjektet: "Nasjonal satsing for utprøving og evaluering av familieråd i Norge" (What about Family Group counselling? Report from the project: Nation. S. Falck. Oslo: Norwegian Social Research Institute (NOVA), 2006:249-83.

21. Havnen KJS, $\varnothing$ C. Knowledge review on Family Group Conferencing: Experiences and outcomes. Regional centre for child and youth mental health and child welfare (RKBU West) uni research health. Norway: Knowledge review on Family Group Conferencing, 2014.

22. Morris K, Connolly M. Family decision making in child welfare: challenges in developing a knowledge base for practice. Child Abuse Review 2012;21:41-52.

23. Shlonsky A, Schumaker K, Cook C. Family group decision making for children at risk of abuse and neglect. The Cochrane. 2009 http://dx. doi.org/10.1002/14651858.CD007984

24. Connolly M. An act of empowerment: the children, young persons and their families act (1989). Br J Soc Work 1994;24:87-100.

25. Schout G, Meijer E, de Jong G, et al. Family Group Conferencing-Its added value in mental health care. Issues Ment Health Nurs 2017;38.

26. Sundell K, Vinnerljung B, Ryburn M. Social workers' attitudes towards family group conferences in Sweden and the UK. Child 2001;6:327-36.

27. Dijkstra S, Creemers HE, Asscher JJ, et al. Family Group Conferencing in Dutch child welfare: Which families are most likely to organize a Family Group Conference? Child Youth Serv Rev 2017;83:255-63.

28. Fronek P. The RAP in rehabilitation: the family conference in practice. Insid This Issue 2008.

29. Fronek P. Insights from the family conference: observations in rehabilitation. Australian Social Work 2005;58:395-406.

30. Loupis YM, Faux SG. Family conferences in stroke rehabilitation: a literature review. J Stroke Cerebrovasc Dis 2013;22:883-93.

31. Hudson P, Thomas T, Quinn K, et al. Family meetings in palliative care: are they effective? Palliat Med 2009;23:150-7.
32. Wisby M, Rosendale E, Gorbien MJ. The family meeting: a benchmark of high-quality geriatric care. Continuum 1996;16:10-17.

33. Reed M, Harding KE. Do family meetings improve measurable outcomes for patients, carers, or health systems? A systematic review. Australian Social Work 2015;68:244-58.

34. Crisp R. Consumer participation in rehabilitation: an unresolved issue. Australian Social Work 1989;42:39-42.

35. Efraimsson E, Sandman PO, Hydén LC, et al. Discharge planning: "fooling ourselves?"-patient participation in conferences. J Clin Nurs 2004;13:562-70.

36. Wright T. Using Family Group Conference in mental health. Nurs Times 2008;104:33-4.

37. de JG, Schout G. Researching the applicability of Family Group Conferencing in public mental health care. Br J Soc Work 2012;43:796-802.

38. de Jong G, Schout G, Meijer E, et al. Enabling social support and resilience: outcomes of Family Group Conferencing in public mental health care. European Journal of Social Work 2016;19:731-48.

39. De Jong G, Schout G, Pennell J, et al. Family Group Conferencing in public mental health and social capital theory. Journal of Social Work 2015;15:277-96.

40. Hillebregt CF, Scholten EWM, Ketelaar M, et al. Effects of family group conferences among high-risk patients of chronic disability and their significant others: study protocol for a multicentre controlled trial. BMJ Open 2018;8:e018883.

41. Malmberg-Heimonen I, Johansen S. Understanding the longer-term effects of family group conferences. European Journal of Social Work 2014;17:556-71.

42. Malmberg-Heimonen I. The effects of Family Group Conferences on social support and mental health for longer-term social assistance recipients in norway. Br J Soc Work 2011;41:949-67.

43. Johansen S. Psycho-Social Processes and Outcomes of Family Group Conferences for long-term social assistance recipients. $\mathrm{Br} J$ Soc Work 2014;44:145-62.

44. Metze RN, Kwekkeboom RH, Abma TA. The potential of Family Group Conferencing for the resilience and relational autonomy of older adults. J Aging Stud 2015;34:68-81.

45. Metze RN. Independence or interdependence, FGC among older adults: FGC, 2016.

46. Moher D, Liberati A, Tetzlaff J, et al. Preferred reporting items for systematic reviews and meta-analyses: the PRISMA statement. Ann Intern Med 2009;151:264-9.

47. Higgins JPT, Green S. Cochrane handbook for systematic reviews of interventions version 5.1.0 Cochrane Collaboration: Wiley-Blackwell, 2011:649.

48. Richardson WS, Wilson MC, Nishikawa J, et al. The well-built clinical question: a key to evidence-based decisions. ACP J Club 1995;123:A12-13.

49. Ouzzani M, Hammady H, Fedorowicz Z, et al. Rayyan-a web and mobile app for systematic reviews. Syst Rev 2016;5:210.

50. Thomas $\mathrm{BH}$, Ciliska $\mathrm{D}$, Dobbins $\mathrm{M}$, et al. A process for systematically reviewing the literature: providing the research evidence for public health nursing interventions. Worldviews Evid Based Nurs 2004;1:176-84.

51. Thomas BH, Ciliska D, Dobbins M, et al. Quality assessment tool for quantitative studies dictionary: the Effective Public Health Practice Project (EPHPP): McMaster Univ, 2008.

52. Howick J, Chalmers I, Glasziou P, et al. Explanation of the 2011 Oxford Centre for Evidence-Based Medicine (OCEBM) levels of evidence (background document). 2011.

53. Sackett DL. Rules of evidence and clinical recommendations on the use of antithrombotic agents. Chest 1986;89:2S-3.

54. Burns PB, Rohrich RJ, Chung KC. The levels of evidence and their role in evidence-based medicine. Plast Reconstr Surg 2011;128:305-10.

55. Cohen J. A coefficient of agreement for nominal scales. Educ Psychol Meas 1960;20:37-46.

56. Hurd C, Curtis J. The intensive care unit family conference. Teaching a critical intensive care unit procedure 2015.

57. Chan EK, O'Neill I, McKenzie M, et al. What works for therapists conducting family meetings: treatment integrity in family-focused grief therapy during palliative care and bereavement. J Pain Symptom Manage 2004;27:502-12.

58. Kroovand Hipple N, McGarrell EF. Comparing police- and civilian-run family group conferences. Policing: An International Journal of Police Strategies \& Management 2008;31:553-77.

59. Keys T. Family Group Decision Making: Implementation and evaluation of outcomes in Oregon. Merkel-Holguin L, 1998 national roundtable on family group decision making, summary of proceedings: Family Group Decision Making, 1999. 
60. Joling KJ, van Marwijk HW, van der Horst HE, et al. Effectiveness of family meetings for family caregivers on delaying time to nursing home placement of dementia patients: a randomized trial. PLoS One 2012;7:e42145.

61. Joling KJ, van Marwijk HW, Smit F, et al. Does a family meetings intervention prevent depression and anxiety in family caregivers of dementia patients? A randomized trial. PLoS One 2012;7:e30936.

62. Joling KJ, Bosmans JE, van Marwijk HW, et al. The costeffectiveness of a family meetings intervention to prevent depression and anxiety in family caregivers of patients with dementia: a randomized trial. Trials 2013;14:305.

63. de Havenon A, Petersen C, Tanana M, et al. A pilot study of audiovisual family meetings in the intensive care unit. J Crit Care 2015;30:881-3.

64. Cohen J. Weighted kappa: nominal scale agreement with provision for scaled disagreement or partial credit. Psychol Bull 1968;70:213-20.
65. Fleiss JL. Statistical methods for rates and proportions. 2nd edn. New York: American Journal of Psychiatry Johm Wiley, 1981.

66. Joling, van Hout vanM, et al. Familiegesprekken met mantelzorgers van dementerenden: Family Meetings in memory clinics, 2007.

67. Joseph-Williams N, Elwyn G, Edwards A. Knowledge is not power for patients: a systematic review and thematic synthesis of patientreported barriers and facilitators to shared decision making. Patient Educ Couns 2014;94:291-309.

68. Pennell J, Burford G. Family group decision making: protecting children and women. Child Welfare 2000;79:131-58.

69. Frost N, Abram F, Burgess H. Family group conferences: evidence, outcomes and future research. Child Fam Soc Work 2014;19:501-7.

70. Lupton C, Nixon P. Empowering practice: a critical appraisal of the family group conference approach. Bristol: Policy Press, 1999.

71. Hoffmann TC, Glasziou PP, Boutron I, et al. Better reporting of interventions: template for intervention description and replication (TIDieR) checklist and guide. BMJ 2014;348:g1687. 